\title{
REVIEW
}

\section{COVID-19 and androgen-targeted therapy for prostate cancer patients}

\author{
Neil A Bhowmick (1),2, Jillian Oft³, Tanya Dorff4, Sumanta Pal4, Neeraj Agarwal5, Robert A Figlin', Edwin M Posadas¹, \\ Stephen J Freedland ${ }^{6}$ and Jun Gong ${ }^{1}$
}

1Department of Medicine, Cedars-Sinai Cancer, Los Angeles, California, USA

2Department of Research, Greater Los Angeles Veterans Administration, Los Angeles, California, USA

${ }^{3}$ Department of Infectious Diseases, Cedars-Sinai Medical Center, Los Angeles, California

${ }^{4}$ Department of Medical Oncology \& Therapeutics Research, City of Hope Comprehensive Cancer Center, Duarte, California

${ }^{5}$ Department of Medicine, University of Utah Huntsman Cancer Institute, Salt Lake City, Utah

${ }^{6}$ Department of Surgery, Cedars-Sinai Cancer, Los Angeles, California

Correspondence should be addressed to J Gong: jun.gong@cshs.org

\begin{abstract}
The current pandemic (COVID-19) caused by severe acute respiratory syndrome coronavirus 2 (SARS-CoV-2) is a global health challenge with active development of antiviral drugs and vaccines seeking to reduce its significant disease burden. Early reports have confirmed that transmembrane serine protease 2 (TMPRSS2) and angiotensin converting enzyme 2 (ACE2) are critical targets of SARS-CoV-2 that facilitate viral entry into host cells. TMPRSS2 and ACE2 are expressed in multiple human tissues beyond the lung including the testes where predisposition to SARS-CoV-2 infection may exist. TMPRSS2 is an androgen-responsive gene and its fusion represents one of the most frequent alterations in prostate cancer. Androgen suppression by androgen deprivation therapy and androgen receptor signaling inhibitors form the foundation of prostate cancer treatment. In this review, we highlight the growing evidence in support of androgen regulation of TMPRSS2 and ACE2 and the potential clinical implications of using androgen suppression to downregulate TMPRSS2 to target SARS-CoV-2. We also discuss the future directions and controversies that need to be addressed in order to establish the viability of targeting TMPRSS2 and/or ACE2 through androgen signaling regulation for COVID-19 treatment, particularly its relevance in the context of prostate cancer management.
\end{abstract}

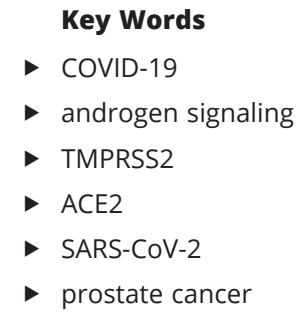

Endocrine-Related Cancer (2020) 27, R281-R292

\section{Introduction}

The current pandemic of coronavirus disease 2019 (COVID-19) is a disease caused by a new coronavirus termed SARS-CoV-2 by the World Health Organization (WHO) and has rapidly spread to at least 114 countries (Park 2020), with nearly 3 million confirmed cases resulting in over 200,000 confirmed deaths as of April 28, 2020 (https://www.who.int/emergencies/diseases/ novel-coronavirus-2019). The clinical spectrum of this novel disease ranges from asymptomatic or mildly symptomatic to severe and critical illness. COVID-19 symptoms include fever, respiratory symptoms (cough and dyspnea), gastrointestinal symptoms (diarrhea and anorexia) (Han et al. 2020), and olfactory and taste disorders (Xydakis et al. 2020). Headache and myalgias are also prominent. It is clear that cancer patients on the whole are at greater risk of contracting COVID-19 and have a poorer prognosis due to a compromised immune system. Patients with severe COVID-19 mount
C) 2020 Society for Endocrinology Published by Bioscientifica Ltd. Printed in Great Britain 
a proinflammatory immune response characterized by excess cytokine production and a paradoxically immunesuppressed state with persistently depressed peripheral T-cell counts (Zhou et al. 2020). Progressive disease leads to acute respiratory distress syndrome (ARDS), multiorgan failure with cardiac complications, thrombosis, and death, prompting multifaceted approaches to mitigation including immunomodulation in addition to antiviral therapy. Increasing epidemiologic data indicate that although the incidence of COVID-19 is similar between genders, the severity and progression of COVID-19 is significantly greater in men than women. One hypothesis to account for this infection discrepancy is that viral entry is potentially enhanced in the lungs and other tissues of men.

The SARS-CoV-2 virus particle is $60-100 \mathrm{~nm}$ in diameter with a single sense strand of nearly $30 \mathrm{~kb}$ of RNA. The cellular entry mechanism involves interaction of a viral spike glycoprotein with transmembrane angiotensin-converting enzyme 2 (ACE2) (Jin et al. $2020 b$ ). The subsequent cleavage of the spike protein by transmembrane protease serine 2 (TMPRSS2) is necessary for viral infection. Both of these proteins are androgen regulated. While other proteases are involved, TMPRSS2 is of particular interest. It is an exquisitely androgen-regulated gene associated with prostate cancer (Bertram et al. 2013). The androgen receptor (AR), and associated signaling, is prominent in prostate tissues as an essential determinant of its development and progression of both benign and adenocarcinoma tissue. Additionally, the inhibition of the androgen signaling axis impacts organs throughout the body inclusive of the lungs. Androgen-targeted therapy may impact susceptibility or mortality risk in prostate cancer patients. This review discusses the current considerations for prostate cancer patients and their treatment in the context of the COVID-19 pandemic, as our understanding of the ramifications of this new prostate cancer comorbidity emerges.

\section{Hypothalamic-pituitary-gonadal axis}

Androgens, in particular testosterone, are critical in the pathogenesis and evolution of prostate cancer as underscored by seminal work by Huggins in the 1940s that formed the theoretical basis for androgen deprivation therapy (Huggins 1942). In a healthy adult male, approximately $90 \%$ of circulating testosterone levels are secreted by Leydig cells in the testes, with about $5-10 \%$ being produced by the adrenal glands. The biosynthesis of testosterone is regulated by the hypothalamic-pituitary-gonadal (HPG) axis whereby pulsatile release of gonadotropin-releasing hormone $(\mathrm{GnRH})$ from the hypothalamus regulates synthesis and secretion of gonadotropins (luteinizing hormone or LH and follicle-stimulating hormone or FSH) from the pituitary gland (Fig. 1). LH, in turn, stimulates synthesis of testosterone in the gonads (testicles). GnRH and LH signaling are inhibited by increasing systemic concentrations of testosterone (Kluth et al. 2014). Testosterone is the primary circulating male hormone with only $1-2 \%$ existing in a free state, the remaining bound to sex-hormone-binding globulin or albumin (Imamoto et al. 2010). DHT is the primary androgen in peripheral tissues resulting from testosterone conversion by the enzyme $5 \alpha$-reductase in the prostate, testes, skin, hair follicles, and adrenals (Imamoto et al. 2008).

Although pulsatile stimulation of the pituitary by $\mathrm{GnRH}$ is required for generation of gonadotropins, continuous stimulation of pituitary $\mathrm{GnRH}$ receptors results in desensitization and downregulation of these receptors with eventual decrease in circulating sex steroids inclusive of androgens (Kluth et al. 2014). This negativefeedback loop serves as the mechanism of action of luteinizing-hormone-releasing hormone (LHRH) agonists, while antagonizing the LHRH receptor represents another method of suppressing testosterone secretion through inhibition of downstream LH signaling (Fig. 1).

\section{Severe acute respiratory syndrome coronavirus 2 (SARS-CoV-2)}

SARS-CoV-2 was originally isolated from the bronchoalveolar lavage fluid of three infected patients from Wuhan in December 30, 2019. It is an enveloped, single-stranded sense RNA virus with a genome size of $29.9 \mathrm{~kb}$ with a nucleoprotein $(\mathrm{N})$ wrapping the RNA genome, forming a coiled tubular structure called the nucleocapsid (Jin et al. 2020b). The viral envelope houses the nucleocapsid and is where several associated structural proteins are located including the spike glycoprotein (S), membrane (M) protein, and envelope (E) protein. The SARS-CoV-2 genome has $5^{\prime}$ and $3^{\prime}$ terminal sequences containing the five essential genes encoding for the four structural proteins with a gene order 5 '-replicase open reading frame (ORF) 1ab-S-envelope(E)membrane(M)-N-3', highly conserved among the $\beta$-coronaviruses (Jin et al. 2020b, Park 2020).

The inflammatory response to infection can potentiate a cytokine storm involving the upregulation 


\section{COVID-19 AND PROSTATE CANCER THERAPY}

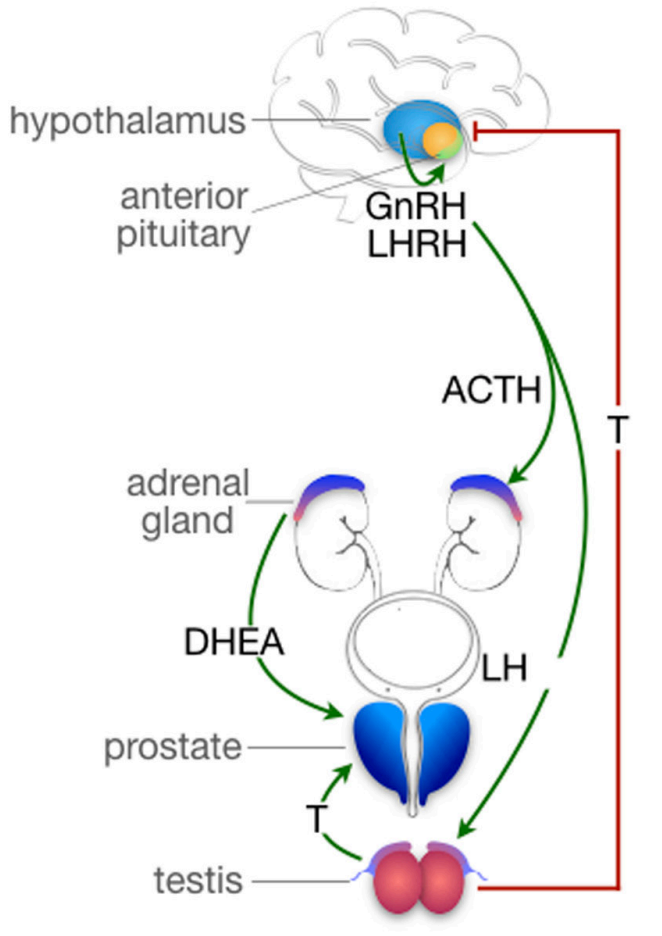

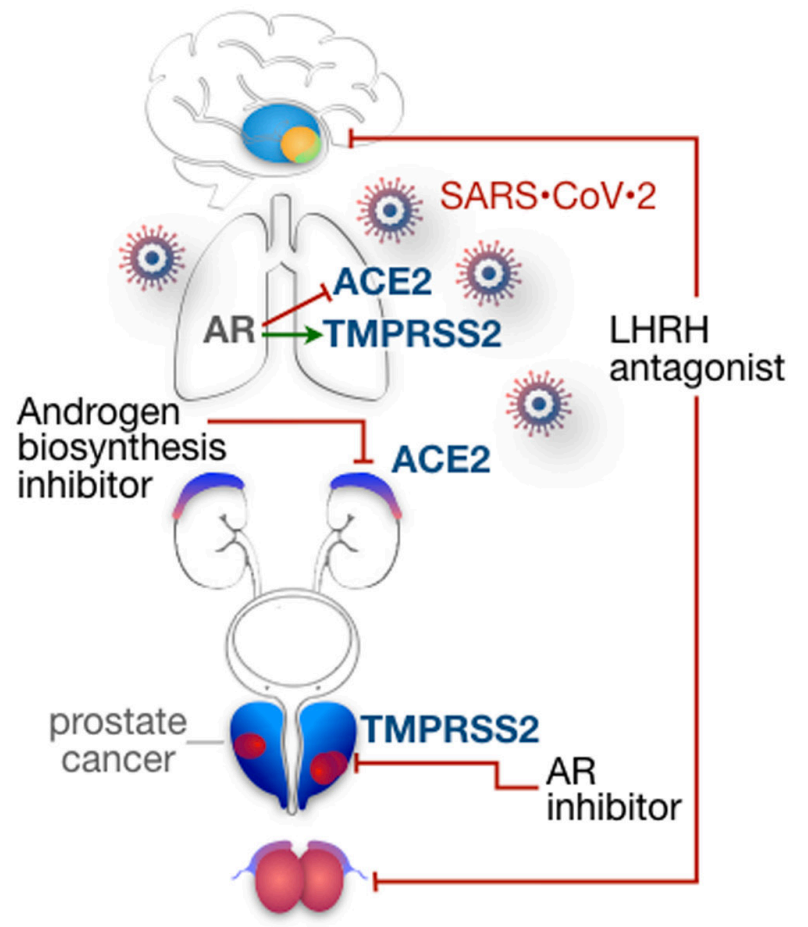

\section{Figure 1}

The hypothalamic-pituitary-gonadal axis in prostate cancer and androgen regulation of TMPRSS2 and ACE2. Left: Pulsatile release of gonadotropinreleasing hormone $(\mathrm{GnRH})$ or luteinizing hormone releasing hormone (LHRH) from the hypothalamus regulates production and release of gonadotropins (luteinizing hormone or LH and follicle-stimulating hormone) from the anterior pituitary gland. LH stimulates testosterone synthesis in the testes, while increasing systemic concentrations of testosterone inhibit GnRH and LH signaling. Androgens, in particular testosterone, are fundamental to the pathogenesis and evolution of prostate cancer. Dehydroepiandrosterone (DHEA) is converted to testosterone and dihydrotestosterone (DHT) in the skin and hair follicles and is produced in the adrenal gland under the control of adrenocorticotropic hormone (ACTH) and in the gonads under the control of $\mathrm{GnRH}$. Right: Continuous stimulation of pituitary GnRH receptors results in desensitization and downregulation of these receptors with eventual decrease in circulating sex steroids inclusive of androgens. This negative-feedback loop serves the basis of androgen deprivation therapy via LHRH agonists, while antagonizing the LHRH receptor represents another method of suppressing testosterone secretion through inhibition of downstream LH signaling. Severe acute respiratory syndrome coronavirus 2 (SARS-CoV-2) viral entry into host cells is dependent on transmembrane serine protease 2 (TMPRSS2) and angiotensin converting enzyme 2 (ACE2), which have been found to be expressed in human lungs and other tissues. TMPRSS2 and ACE2 appear to be androgen-regulated genes where androgen receptors are expressed in human lungs. Androgen receptor (AR) signaling has been shown to increase TMPRSS2 expression while decreasing ACE2 expression. Thus, while SARS-CoV-2 could be putatively targeted through TMPRSS2 and androgen signaling suppression (a standard treatment paradigm in prostate cancer), ACE2 expression may be enhanced with androgen suppression. It is unknown whether this would result in a net increase in risk for severe infection or a potential benefit from preserving the protective effects of ACE2 protein expression, while hindering a key step in conformational change and viral entry to nonimmune cells.

of tumor necrosis factor- $\alpha(\mathrm{TNF} \alpha)$, interleukin $1 \beta$ (IL-1 $\beta)$, IL-6, monocyte chemoattractant protein-1 (MCP-1), and macrophage inflammatory proteins 1- $\alpha$ (MIP1 $\alpha)$. Although the source of the cytokine storm is not yet clear contributing to the multi-organ dysfunction, uncontrolled viral replication and deleterious inflammatory responses may both contribute to tissue damage evident in the lungs. In later stages of disease, evidence of abnormal coagulation with prothrombotic tendency is a poor prognostic factor. The elevated expression of ACE2 on vascular endothelia is thought to be a potential mechanism for the coagulation and associated hypotension (Lukassen et al. 2020).
However, the predominant site of ACE2 expression is on type II alveolar (AT2) cells of the lung, resulting in the greatest damage to these cells during SARS-CoV-2 infection. Long-term outcomes of lung damage caused by SARS-CoV-2 are not yet well-described as most patients are still in the early stages of infection or recovery, but based on our knowledge of ARDS in other infections including influenza, recovery can be protracted, with lasting fibrosis. Other organ systems including the heart, digestive, and urinary tracts have been shown to express ACE2 and may serve as additional at-risk targets for SARS-CoV-2 (Zou et al. 2020). Thus, infection prevention is the holy grail. 


\section{SARS-CoV-2 transmission, host entry, and antigenicity}

All human coronavirus infections are caused by two of four subfamilies of coronaviruses, the $\alpha$ - and $\beta$-coronaviruses; these viruses cause respiratory, hepatic, neurologic, and enteric diseases (Jin et al. 2020b). Respiratory secretions or droplets and direct contact have been recognized as the main modes of SARS-CoV-2 transmission, while reports exist of fecal-oral transmission (Jin et al. 2020b, Park 2020). The transmissibility of SARS-CoV-2 through aerosols and vertical transmission remains poorly described (Jin et al. $2020 b$, Park 2020). The mean incubation period has been shown to be 5.2 days (95\% CI or CI 4.1-7.0) with a basic reproductive number estimated to be 2.2 (95\% CI 1.4-3.9) (Li et al. 2020b).

Early investigations identified that ACE2 was expressed in human airway epithelia with more abundant expression in the apical surface and well-differentiated cells and served as the functional receptor for viral entry into host cells for the original SARS-CoV (Jia et al. 2005). It has been shown that human ACE2 also mediates SARS-CoV-2 entry into host cells through tight binding of the viral $\mathrm{S}$ protein domain $\mathrm{B}\left(\mathrm{S}^{\mathrm{B}}\right)$ to human ACE2 (Walls et al. 2020). In elegant sequencing studies of SARS-CoV-2, the presence of a furin cleavage site at the $\mathrm{S}_{1} / \mathrm{S}_{2}$ boundary that is processed during viral biosynthesis sets SARS-CoV-2 apart from SARS-CoV and may enhance the tissue tropism and/or transmissibility of SARS-CoV-2 compared to SARS-CoV given the near-ubiquitous distribution of furin-like proteases in the human body (Walls et al. 2020). The cellular serine protease, TMPRSS2, mediates $S$ protein cleavage at the $S_{1} / S_{2}$ site, seemingly a required priming event for subsequent SARS-CoV-2 interaction with ACE2 and cell entry (Hoffmann et al. 2020). Co-expression of ACE2 and TMPRSS 2 has been identified in type II pneumocytes, absorptive enterocytes of the small intestine, and nasal goblet secretory cells, all typical sites of COVID-19 symptoms (Ziegler et al. 2020).

Because of its crucial role in cell entry and viral propagation, the coronavirus $\mathrm{S}$ glycoprotein is suspected to be the primary target of neutralizing antibodies following infection and is the focus of current therapeutic and vaccine designs. Mapping of the $S$ protein demonstrated a more conserved $S_{2}$ subunit, while the $S_{1}$ subunit showed the highest divergence given that it is more exposed at the viral surface and potentially subjected to more selection pressure from the host immune system. Given that the SARS-CoV-2 and SARS-CoV SB domains share $75 \%$ amino acid sequence identity and most SARS-CoV neutralizing antibodies target the $S^{\mathrm{B}}$ receptor-binding domain, crossreactivity across coronaviruses may not necessarily be achieved (Yuan et al. 2020).

\section{COVID-19 clinical presentation}

In the initial cohort of 41 patients diagnosed with laboratory-confirmed SARS-CoV-2, majority of the infected patients were aged 25-49 (49\%) with a median age of 49.0 years and male (73\%) (Huang et al. 2020). The median time from onset of illness to shortness of breath or dyspnea was 8.0 days (interquartile range or IQR 5.0-13.0), 7.0 days (IQR 4.0-8.0) for hospital admission, and 9.0 days for ARDS (IQR 8.0-14.0). Laboratory parameters showed leukopenia (white blood cell or WBC count less than $4 \times 10^{9} / \mathrm{L}$ ) in $25 \%$, lymphopenia (lymphocyte count $<1.0 \times 10^{9} / \mathrm{L}$ ) in $63 \%$, elevated lactate dehydrogenase (LDH, $>245 \mathrm{U} / \mathrm{L}$ ) in $73 \%$, elevated aspartate aminotransferase $(>40 \mathrm{U} / \mathrm{L})$ in $37 \%$, and a normal procalcitonin level $(<0.1 \mathrm{ng} / \mathrm{mL})$ in $69 \%$. On admission, abnormalities in chest CT were detected in all patients with bilateral involvement of the lungs in $98 \%$ of patients. The most common complications included ARDS (29\%), acute cardiac injury (12\%), and secondary infection (10\%) with mechanical ventilation required in $10 \%$ of patients. At the time of their report, $68 \%$ of patients had been discharged, while $15 \%$ had died (Huang et al. 2020)

Higher levels of prothrombin time and D-dimer on admission were also identified in patients requiring intensive care unit (ICU) care compared to non-ICU patients (Huang et al. 2020). Indeed, coagulopathy has emerged as a key aspect impacting COVID-19 mortality (Tang et al. 2020), although it is unclear yet whether this is different in male vs female patients. Initial plasma concentrations of IL-2, IL-7, IL-10, GCSF, CXCL10, CCL2, CCL3, and TNF $\alpha$ were also higher in ICU patients than non-ICU patients (Huang et al. 2020), raising the potential that innate immune factors contribute to severity of the COVID-19 course. Notably, there are known influences of androgens and estrogens on immune biology relating specifically to viral infection which may be important (Klein 2012). Influences of sex hormones also act differently in men and women, accounting, in part, for the persistent differences in male patients and post-menopausal women. In both the Italian and Chinese datasets, there was higher incidence of severe disease in male patients; of 355 fatal COVID-19 cases in Italy, 30\% were women (Onder et al. 2020). In all the aforementioned series, fatal cases occurred more often in patients with https://erc bioscientifica.com https://doi.org/10.1530/ERC-20-0165 (c) 2020 Society for Endocrinology Published by Bioscientifica Ltd. Printed in Great Britain 
diabetes (20-35\% compared to $<10 \%$ in non-fatal cases), coronary artery disease (10-30\% compared to about $10 \%)$, and $20 \%$ had active cancer in the Italian series (Onder et al. 2020). Future studies may reveal the cumulative impact of the inflammatory and metabolic insults on prostate cancer progression.

\section{Mechanisms of SARS-CoV-2 and gonadal dysfunction}

There is growing evidence to suggest that the testes may be predisposed for damage by SARS-CoV-2. ACE2 expression in tissues has previously been shown to be programmable by stresses including hypertension, whereby the lungs were the only site of increased ACE2 activity in preclinical models (Riviere et al. 2005). A separate group using adult human testis single-cell RNA sequencing datasets identified that ACE2 was primarily enriched in spermatogonia and Leydig and Sertoli cells (the latter group of Leydig and Sertoli cells could not be separated into individual clusters on analysis), whereas early spermatocytes, late spermatocytes, spermatids and other somatic cells had very low expression levels of ACE2 (Wang \& Xu 2020). Interestingly, ACE2 expression in Leydig and Sertoli cells was three-fold higher compared to ACE2-expressing AT2 cells $(4.25 \%$ vs $1.40 \%)$. Further analysis showed that ACE2-positive spermatogonia express a higher number of genes associated with viral reproduction and transmission with a lower number of genes related to spermatogenesis compared to ACE2-negative spermatogonia, while ACE2positive Leydig and Sertoli cells express a higher number of genes involved in cell-cell junction and immunity with a lower number of genes associated with mitochondria and reproduction (Wang \& Xu 2020). A second study has illustrated that high ACE2 expression was found in seminiferous ducts and Leydig cells of the testes as well (Fan et al. 2020).

Preclinical work demonstrated that overexpression of TMPRSS2 to approximately ten-fold higher than normal human lung tissues conferred high susceptibility to SARS-CoV-2 infection compared to control (Fan et al. 2020). Moreover, one group using adult human testis single-cell RNA sequencing demonstrated that TMPRSS2 expression was concentrated in spermatogonia and spermatids with relatively low levels in other cell types of the testis (Wang \& Xu 2020). The constellation of these findings suggest that the testis may represent a high-risk organ vulnerable to SARS-CoV-2 infection that could result in spermatogenic failure. As described earlier, this process is likely mediated by SARS-CoV-2 S protein binding to ACE2 and $S$ protein priming by TMPRSS2 (Hoffmann et al. 2020), of which these two critical targets for viral entry are specifically expressed in male gonads.

\section{SARS-CoV-2, androgen regulation, and prostate cancer}

The impact of SARS-CoV-2 infection on male gonadal function was first described in a retrospective series by Ma et al. (2020). In this single-institution study, 81 male patients with laboratory-confirmed SARS-CoV-2 infection underwent evaluation of serum sex hormone levels that were compared to 100 age-matched healthy men. The median age of the SARS-CoV-2 group was 38 years with $14.81 \%, 44.44 \%, 33.33 \%$, and $51.85 \%$ having received corticosterone, arbidol, oseltamivir, and i.v. antibiotics, respectively. Thirty-one patients (38.27\%) in this group had elevated serum alanine transaminase and/or serum aspartate transaminase. Compared to agematched healthy male controls, those with SARS-CoV-2 infections had significantly higher serum LH $(P<0.0001)$ and serum prolactin $(P<0.0001)$. Whereas there was no statistical difference between serum testosterone or FSH levels between groups, there was a significantly decreased testosterone:LH ratio $(P<0.0001)$ and FSH:LH ratio $(P<0.0001)$ seen in the SARS-CoV-2-positive group. On multivariable analysis, $C$ reactive protein levels were significantly associated with serum testosterone:LH ratio in SARS-CoV-2 patients $(P=0.0128)$. It is worthwhile to note that this study was limited by its retrospective nature, relatively small sample size, lack of confirmation of SARS-CoV-2 in semen or testes, proportion of steroid use and potential other factors influencing the HPG axis (e.g. stress), and uncertainty of timepoint of collection of samples. As more recently the presence of SARS-CoV-2 was identified in semen of infected men (Li et al. 2020a), the compelling analysis implicate SARS-CoV-2-infected males impaired testosterone production may stimulate $\mathrm{LH}$ release to maintain testosterone levels during early stages of hypogonadism based on negative-feedback regulation (Ma et al. 2020). This phenomenon may be one explanation for the dramatically decreased testosterone:LH ratios observed compared to age-matched controls. Furthermore, the authors argue that the observed elevated prolactin levels in infected males could contribute to pituitary suppression and decreased gonadotropins, but prolactin secretion can be affected by a multitude of factors, in general. FSH is 
mainly suppressed by inhibin B from Sertoli cells and, given that there was no statistically significant difference in FSH levels between infected and healthy men, Leydig cells rather than Sertoli cells appear more susceptible to injury from SARS-CoV-2.

The original form of androgen deprivation therapy as described by Huggins, bilateral orchiectomy, remains in use worldwide, but has largely been replaced by pharmaceutical castration via manipulation of the HPG axis as the cornerstone of prostate cancer therapy where such drugs are available. The recent treatment landscape for prostate cancer has evolved with the advent of agents that target the androgen signaling pathway by direct antagonism of the receptor or specific inhibition of CYP17. This broader class of agents that inactivate the androgen signaling pathway is better described as androgen-targeted therapy (Crawford et al. 2019), but will be briefly summarized subsequently.

First-generation oral nonsteroidal antiandrogens such as bicalutamide, flutamide, and nilutamide that compete with DHT for binding AR are associated with a moderate rise in testosterone. Hence, these agents are most commonly used in combination with LHRH agonists to reduce the impact of a testosterone surge (Boccardo 2000, Crawford et al. 2019). Leuprolide acetate (LUPRON $\left.{ }^{\circledR}\right)$ is among the most common LHRH agonists used in the achieving testosterone levels below the US Food and Drug Administration (FDA) defined castration level of $50 \mathrm{ng} / \mathrm{dL}$ in $93-100 \%$ of patients receiving the drug, usually by day 21 (Crawford et al. 2019). As with leuprolide, goserelin acetate (ZOLADEX ${ }^{\circledR}$ ) is another LHRH analog that is associated with a testosterone rise during the first week, but fall within castrate range $(<3 \mathrm{nmol} / \mathrm{L})$ by 21 days (Cockshott 2000). A LHRH antagonist, degarelix (FIRMAGON ${ }^{\circledR}$ ), is approved for the treatment of advanced prostate cancer and is available as a once monthly s.c. dose and competitively binds to the LHRH receptor that inhibits downstream LH signaling and suppresses testosterone without an initial testosterone surge seen with LHRH agonists (Klotz et al. 2008). Degarelix has been shown to achieve castrate levels of testosterone $(\leq 0.5 \mathrm{ng} / \mathrm{mL})$ within $1-3$ days of administration in 99-100\% of patients (Klotz et al. 2008). Abiraterone acetate $\left(\mathrm{ZYTIGA}^{\circledR}\right)$ is an oral, androgen biosynthesis inhibitor that blocks testosterone production through inhibition of the enzyme CYP17 (O'Donnell et al. 2004, Attard et al. 2008). It is most commonly combined with prednisone and LHRH agonists to reduce androgen production from all sources including the testes, adrenal glands, and prostate cancer cells. In castrate-naive prostate cancer patients (testosterone level of $>9 \mathrm{nmol} / \mathrm{L}$ ), treatment with abiraterone results in castrate levels of testosterone $(\leq 2.0 \mathrm{nmol} / \mathrm{L})$ rapidly but often is not sustained beyond 3 days (O'Donnell et al. 2004). Notably, the combination of abiraterone and LHRH agonists (leuprolide) profoundly suppresses testosterone levels to those generally seen with LHRH agonists alone (Taplin et al. 2014). Next-generation orally available nonsteroidal androgen receptor inhibitors enzalutamide (XTANDI $\left.{ }^{\circledR}\right)$, apalutamide (ERLEADA ${ }^{\mathrm{TM}}$ ) and darolutamide (NUBEQA ${ }^{\mathrm{TM}}$ ) competitively bind the ligandbinding domain of the AR to limit nuclear translocation and downstream signaling. The principal gonadal suppressing effects are likely from the LHRH agonism given that monotherapy studies of enzalutamide in castrate-naive (testosterone levels $\geq 230 \mathrm{ng} / \mathrm{dL}$ ) prostate cancer patients show that testosterone levels rise sharply between 1 and 5 weeks, after which testosterone leveled off between 13 and 49 weeks with enzalutamide (Tombal et al. 2015). Apalutamide and darolutamide have limited penetration in the CNS compared to enzalutamide, suggesting a lower tendency to affect the HPG axis (Clegg et al. 2012, Moilanen et al. 2015). Infectious complications were not noted to be higher in phase III randomized trials, suggesting no clinically relevant immune compromise associated with androgen receptor targeting. The impact of these agents on overall immune function has not been well described.

\section{Clinical relevance of SARS-CoV-2 and androgen suppression in prostate cancer}

Although men and women have a similar susceptibility to SARS-CoV-2, men appear to be more prone to greater disease severity and mortality independent of age (Jin et al. 2020a). TMPRSS2 gene fusions have historically been shown to contribute to prostate tumorigenesis, with approximately $50 \%$ of prostate cancer cases being positive for TMPRSS2-ERG fusions (Tomlins et al. 2008). Being that TMPRSS2 is an androgen-responsive gene, one group analyzed publicly available genomic datasets and determined that TMPRSS2 mRNA expression levels in human normal lung samples in men were higher than those in women $(P=0.029)$ (Asselta et al. 2020). In searching for genetic variants of TMPRSS2 that could account for variations in disease severity in the European population (particularly in Italy where SARS-CoV-2 cases and mortality are among the highest in the world), a frequent European haplotype linked to a known androgenresponsive enhancer for TMPRSS2 and thus expected 
to upregulate TMPRSS2 in an androgen-dependent manner was virtually absent in the Asian population. A second haplotype was also significantly increased in Italians compared to East Asians and was putatively associated with higher TMPRSS2 expression. Of four single nucleotide polymorphisms (SNPs) found to significantly differ between the Italian population and East Asians, one was found to be of lower frequency in Italians compared to East Asians and other Europeans. Interestingly, this one variant involved a missense substitution of an exon variant, p.Val160Met, which affects a residue far from the serine protease catalytic triad and has been associated with genomic rearrangements in TMPRSS2 and highrisk prostate cancer (Asselta et al. 2020). In an Italian population where the male cancer patients had a higher risk of having COVID-19 ( $n=4532$; OR 1.79; CI 1.62-1.98), Montololi et al. recently reported that ARSIs may provide partial protection from SARS-CoV-2 infection (Montopoli et al. 2020). Of note, although one group identified a higher homozygous mutation rate of ACE2 in males than females, ACE2 mRNA expression levels in the lung from a large dataset were not substantially different between males and females (Asselta et al. 2020, Cao et al. 2020).

This collection of data of a more aggressive course of COVID-19 in men that is possibly associated with TMPRSS2 expression and androgen regulation can suggest an intriguing possibility where androgen signaling influences disease severity and mortality with SARS-CoV-2 infection. It has been well documented that TMPRSS 2 is expressed in the lung and human epithelial airway cells where its activity is important to facilitate viral entry into host cells for human coronaviruses including SARS-CoV-2 (Bertram et al. 2013, Hoffmann et al. 2020). However, lung tissues in mice and humans did not support TMPRSS 2 as a determinant of sex differences in SARS-CoV-2 infection as there were similar levels of gene expression in males and females (Baratchian et al. 2020, Stopsack et al. 2020). Other studies have shown that camostat mesylate, a clinically proven serine protease inhibitor that is active against TMPRSS2, inhibited SARS-CoV-2 S protein-driven viral entry into TMPRSS2-expressing human lung cell lines, but not in TMPRSS2-null cell lines (Hoffmann et al. 2020). The decreased infection with SARS-CoV-2 supported TMPRSS2 as a viable target in the treatment of SARS-CoV-2.

Androgen receptors have been shown to be present in both normal human lungs and lung cancer specimens where administration of androgens in cultured human lung cancer cells resulted in a significant upregulation of TMPRSS2 with androgen-dependent loading of the
AR protein onto the TMPRSS2 enhancer (Mikkonen et al. 2010). Conversely, mining of public genomic datasets has shown that treatment with estradiol (prolonged) or AR antagonists (i.e. enzalutamide) significantly downregulated TMPRSS2 (Wang et al. 2020). As expected, TMPRSS2 expression increased between 1.4- and 20-fold following treatment with androgens, synthetic androgens, or short-doses of estradiol. In addition to estrogen and androgen-related compounds, other treatments that decreased TMPRSS 2 expression included dual TGF- $\beta$ and EGF treatment (Wang et al. 2020).

Chromosomal rearrangements fusing the androgenregulated gene TMPRSS 2 to the oncogenic ETS transcription factor $E R G$ occurs in about 50\% of prostate cancers and attenuates androgen signaling through direct inhibition of AR expression and downregulating AR signaling at genespecific loci (Yu et al. 2010). In preclinical prostate cancer models, ERG overexpression represses AR-target genes and significantly suppresses TMPRSS2 when comparing ERG+ tumors to ETS-prostate tumors (Yu et al. 2010). Accordingly, knockdown of $E R G$ resulted in $A R$ upregulation. This is of potential significance given that one SNP that has been associated with genomic rearrangements in TMPRSS2 and high-risk prostate cancer was found in significantly lower frequency in an Italian cohort, a group with notably higher COVID-19 incidence and mortality (Asselta et al. 2020). Altogether, these results possibly indicate that expression of TMPRSS2, a target of SARS-CoV-2, in human lungs is modulated by estrogens and androgens and can be repressed by treatment with estrogens or androgenreceptor antagonists as a therapeutic strategy against COVID-19. Men receiving ARSI therapy because of their diagnosed TMPRSS2:ERG fusion expressing prostate cancer may represent a subgroup of patients with reduced infectivity by SARS-CoV-2 and a lesser disease severity with COVID-19.

ACE2 is recognized as both the entry receptor and serving a lung protective function from injury to human coronaviruses including SARS-CoV-2. Viral $S$ protein binding and downregulation of ACE2 may promote excess angiotensin II production and enhanced lung vascular permeability, acute lung injury, and tissue damage (Imai et al. 2005). Using VeroE6 cells, treatment with clinical-grade human recombinant soluble ACE2 (hrsACE2), which has already been tested in phase 1 and phase 2 clinical trials, significantly inhibited SARS-CoV-2 infection in a dose-dependent manner as compared to controls. Treatment with mouse recombinant soluble ACE2 did not inhibit the infection. Inhibition of SARS-CoV-2 infection was also demonstrated with (c) 2020 Society for Endocrinology Published by Bioscientifica Ltd. Printed in Great Britain 
hrsACE2 treatment in human capillary and kidney organoids that modeled the ability of the virus to infect blood vessels prior to local organ infections (Monteil et al. 2020).

Androgen axis regulation also appears to affect ACE2 expression. In early animal studies, testosterone and DHT downregulated ACE2 mRNA and protein expression in the vasculature in an ERK1/2 MAP kinase-signaling dependent manner, while testosterone withdrawal by castration significantly elevated ACE2 mRNA and protein levels (Mishra et al. 2016). A separate study has shown that chronic blockade of the androgen receptor with the antiandrogen flutamide in the absence of a change in estradiol significantly increased renal ACE2 mRNA expression in rats compared to control (Dasinger et al. 2016). In an analysis of RNA-sequencing/microarray datasets, transgender males who underwent androgen targeted therapy for 1 year showed significantly higher ACE2 expression and more ACE2-expressing cells among Sertoli cells in the testis (Chen et al. 2020). However, cellline screens for transcriptional inhibitors of ACE2 have shown that the synthetic androgen R1881 was among the compounds that upregulated ACE2, although ACE2 expression was poorly expressed in cell lines profiled by the drug transcriptome screen (Wang et al. 2020). Therefore, although SARS-CoV-2 may be targeted through TMPRSS2 and androgen signaling suppression, developing a similar approach through androgen suppression and ACE2 is less clear. Evidence to date suggests that ACE2 expression may be enhanced with androgen suppression. It is unknown whether this would result in a net increase in risk for severe infection or a potential benefit from preserving the protective effects of ACE2 protein expression, while hindering a key step in conformational change and viral entry to nonimmune cells. Further understanding of these factors is essential to optimizing use of androgen suppression in the setting of SARS-CoV-2.

\section{Current management of prostate cancer during the COVID-19 pandemic and controversies}

Androgen signaling inhibition is a hallmark treatment strategy for prostate cancer across multiple stages of disease. Despite the previously described evidence in support of a potential and serendipitous therapeutic strategy against SARS-CoV-2 by targeting TMPRSS2 in human lung tissue using a standard therapy in prostate cancer patients, where do we stand in its clinical application during the current COVID-19 pandemic? Further investigation is certainly needed prior to clinical application. First, it would be beneficial through observational or retrospective analyses to describe the impact of TMPRSS2 expression in non-tumor lung tissues from patients with prostate cancer treated with AR signaling inhibitors and those from individuals with normal androgen levels. If the data are supportive, clinical trials could be rapidly implemented to test the strategy of downregulating TMPRSS2 by androgen suppression as a treatment for COVID-19 given the widespread use, familiarity with the safety profiles, and knowledge of the onset of androgen suppression of classical androgen-deprivation drugs (e.g. leuprolide) and oral AR signaling inhibitors (e.g. enzalutamide, apalutamide, or darolutamide) that are currently used in prostate cancer treatment.

However, the impact of androgen signaling suppression on ACE2, another critical target of SARS-CoV-2 infectivity, would also need to be further evaluated across larger populations. Preclinical work suggests that chronic androgen blockade could, in fact, upregulate ACE2 expression and this potentially negative consequence would need to be counter-balanced in considering its effect on the severity and mortality from COVID-19. Leuprolide is also a frequently used drug in fertility preservation for women. The role of estrogen in mediating infection by SARS-CoV-2 needs to be evaluated, particularly through its impact on viral entry receptors in the lung. Estrogen therapy significantly increases ACE2 expression in the mouse thymus and human testes, while estrogen has been shown to exert a tissue-specific effect by regulating ACE2 expression in the kidneys, but not in lungs (Mishra et al. 2016, Chen et al. 2020). Additional study on a broader level of how androgens and estrogens impact immune biology and how sex hormones between men and women differentially influence viral infection is beyond the scope of this review but is certainly warranted amid the current pandemic. Within this topic, one could also look into whether hormone levels in an older population affect the expression of ACE2 and TMPRSS2 and/or risk of SARS-CoV-2 infection when compared to a younger population. Moreover, the effects of SARSCoV-2 on gonadal function in humans are limited to one retrospective study, with its effects on gonadal function in human subjects with prostate cancer treatment unknown. The long-term impact on gonadal function in humans infected with SARS-CoV-2 needs to be established. Beyond the acute phase of COVID-19, the theoretical implications of long-term, chronic effects of SARS-CoV-2-related gonadal suppression for therapeutic efficacy in prostate cancer patients would also be an area of particular interest. https://erc bioscientifica com https://doi.org/10.1530/ERC-20-0165 c) 2020 Society for Endocrinology Published by Bioscientifica Ltd. Printed in Great Britain 


\section{Current prostate cancer management recommendations}

Cancer patients and cancer survivors are an at-risk population for COVID-19 with a pooled prevalence of 2.0\% (Desai et al. 2020). The infection rate of SARS-CoV-2 in patients with cancer from a single-institution series is higher $(0.79 \%)$ than the cumulative incidence of all diagnosed COVID-19 cases in the city of Wuhan over the same period (0.37\%) (Yu et al. 2020). In general, patients with metastatic cancers infected with COVID-19 have had poorer outcomes including death, admission to the intensive care unit, requiring mechanical ventilation, and severe symptoms; patients with COVID-19 and nonmetastatic (stages I-III) cancer had similar outcomes in patients without cancer (Dai et al. 2020, Liang et al. 2020).

Until the areas of controversy with respect to androgen suppression and TMPRSS 2 and ACE2 are addressed, expert consensus or national oncology practice guidelines for use of androgen-targeted therapy in prostate cancer during the COVID-19 pandemic are a resource and can be followed (Hanna et al. 2020, Kutikov et al. 2020, National Comprehensive Cancer Network 2020), whereby: (1) androgen-deprivation therapy should be avoided in those with very low-, low-, and intermediate-risk prostate cancer; (2) avoid initiating androgen-deprivation therapy for patients with a prostate-specific antigen (PSA) doubling time of $>9$ months in non-metastatic disease; (3) consider neoadjuvant androgen deprivation therapy for up to 4-6 months as necessary in asymptomatic, unfavorable intermediate risk and high-risk prostate cancer patients planned for definitive radiation therapy (RT); (4) prioritize androgen-deprivation therapy and other nonmyelosuppressive regimens when alternatives exist to minimize risk of immunosuppression and infectious complications for symptomatic or advanced prostate cancer patients; and (5) 3-, 4-, or 6-month formulations of androgen-deprivation therapy should be preferred over 1-month injections in all cases.

\section{Conclusions and future directions}

As development of antiviral drugs and vaccines against SARS-CoV-2 are underway during the COVID-19 pandemic, androgen regulation of TMPRSS2 and ACE2 as a means to inhibit SARS-CoV-2 viral entry and thus infection may represent a novel strategy in treating COVID-19. This concept would be serendipitous for men with prostate cancer being treated by this foundational therapeutic strategy used for decades. A growing concern is the explosion of early reports on the prognosis of cancer patients, efficacy of therapeutic interventions for COVID-19, and safety of anticancer therapies during the COVID-19 pandemic that have produced conflicting results and are, for the most part, non-peer reviewed. It would be important to compile all these fragmented studies into systemic registries for comprehensive retrospective analyses and to inform future studies. In the current era with social media and internet technology, the importance of crowdsourcing cannot be underestimated as a tool to assist in disaster risk reduction and emergency management through information dissemination, data monitoring, and the direct engagement of diverse sets of actors to spur riskreduction efforts (Alexander 2014, Wukich 2015). Given this lack of knowledge and concern for extreme vulnerability in cancer patients, the COVID-19 and Cancer Consortium (CCC19) was formed. This national collaborative effort began organically, primarily through social media channels but has grown to more than 65 physicians and nurses representing over 30 institutions and organizations in the United States. Most institutional members are large NCI-designated comprehensive cancer centers. The driving goal of the consortium is to collect prospective, granular, uniformly organized information on cancer patients infected with COVID-19 as rapidly as possible (https://ccc19.org/). While this review is being written during the first wave of COVID-19 infection in the United States, there will inevitably be many more to follow where prostate cancer patients, and cancer patients as a whole, may not be spared. Efforts to guide the management of these at-risk patients and the safe delivery of systemic anticancer therapies will require a concerted effort by a multidisciplinary task force.

\section{Funding}

This work was supported by grants from the Department of Defense (W81XWH-19-1-0388 to N A B and W81XWH-19-1-0406 to J G), the National Cancer Institute (CA233452 to N A B), and US Department of Veterans Affairs (BX001040 to N A B).

\section{Declaration of interest}

The authors declare no conflict of interest that could be perceived as prejudicing the impartiality of the research reported. (c) 2020 Society for Endocrinology Published by Bioscientifica Ltd. Printed in Great Britain 


\section{References}

Alexander DE 2014 Social media in disaster risk reduction and crisis management. Science and Engineering Ethics 20 717-733. (https://doi. org/10.1007/s11948-013-9502-z)

Asselta R, Paraboschi EM, Mantovani A \& Duga S 2020 ACE2 and TMPRSS2 variants and expression as candidates to sex and country differences in COVID-19 severity in Italy. Aging 12 10087-10098. (https://doi.org/10.18632/aging.103415)

Attard G, Reid AH, Yap TA, Raynaud F, Dowsett M, Settatree S, Barrett M, Parker C, Martins V, Folkerd E, et al. 2008 Phase I clinical trial of a selective inhibitor of CYP17, abiraterone acetate, confirms that castration-resistant prostate cancer commonly remains hormone driven. Journal of Clinical Oncology 26 4563-4571. (https://doi. org/10.1200/jco.2007.15.9749)

Baratchian M, McManus J, Berk M, Nakamura F, Erzurum, Mukhopadhyay S, Drazba J, Peterson J, Gaston B \& Sharifi N 2020 No evidence that androgen regulation of pulmonary TMPRSS2 explains sex-discordant COVID-19 outcomes. bioRxiv [epub]. (https:// doi.org/10.1101/2020.04.21.051201)

Bertram S, Dijkman R, Habjan M, Heurich A, Gierer S, Glowacka I Welsch K, Winkler M, Schneider H, Hofmann-Winkler H, et al. 2013 TMPRSS2 activates the human coronavirus 229E for cathepsinindependent host cell entry and is expressed in viral target cells in the respiratory epithelium. Journal of Virology 87 6150-6160. (https:// doi.org/10.1128/jvi.03372-12)

Boccardo F 2000 Hormone therapy of prostate cancer: is there a role for antiandrogen monotherapy? Critical Reviews in Oncology/Hematology 35 121-132. (https://doi.org/10.1016/s1040-8428(00)00051-2)

Cao Y, Li L, Feng Z, Wan S, Huang P, Sun X, Wen F, Huang X, Ning G \& Wang W 2020 Comparative genetic analysis of the novel coronavirus (2019-nCoV/SARS-CoV-2) receptor ACE2 in different populations. Cell Discovery 6 11. (https://doi.org/10.1038/s41421-020-0147-1)

Chen J, Jiang Q, Xia X, Liu K, Yu Z, Tao W, Gong W \& Han J 2020 Individual variation of the SARS-CoV-2 receptor ACE2 gene expression and regulation. Aging Cell [epub]. (https://doi. org/10.1111/acel.13168)

Clegg NJ, Wongvipat J, Joseph JD, Tran C, Ouk S, Dilhas A, Chen Y, Grillot K, Bischoff ED, Cai L, et al. 2012 ARN-509: a novel antiandrogen for prostate cancer treatment. Cancer Research $\mathbf{7 2}$ 1494-1503. (https://doi.org/10.1158/0008-5472.can-11-3948)

Cockshott ID 2000 Clinical pharmacokinetics of goserelin. Clinical Pharmacokinetics 39 27-48. (https://doi.org/10.2165/00003088200039010-00003)

Crawford ED, Heidenreich A, Lawrentschuk N, Tombal B, Pompeo ACL, Mendoza-Valdes A, Miller K, Debruyne FMJ \& Klotz L 2019 Androgen-targeted therapy in men with prostate cancer: evolving practice and future considerations. Prostate Cancer and Prostatic Diseases 22 24-38. (https://doi.org/10.1038/s41391-018-0079-0)

Dai M, Liu D, Liu M, Zhou F, Li G, Chen Z, Zhang Z, You H, Wu M, Zheng Q et al. 2020 Patients with cancer appear more vulnerable to SARS-CoV-2: a multi-center study during the COVID-19 outbreak. Cancer Discovery [epub]. (https://doi.org/10.1158/2159-8290.cd-20-0422)

Dasinger JH, Intapad S, Rudsenske BR, Davis GK, Newsome AD \& Alexander BT 2016 Chronic blockade of the androgen receptor abolishes age-dependent increases in blood pressure in female growth-restricted rats. Hypertension 67 1281-1290. (https://doi. org/10.1161/hypertensionaha.116.07548)

Desai A, Sachdeva S, Parekh T \& Desai R 2020 COVID-19 and cancer: lessons from a pooled meta-analysis. Journal of Global Oncology 6 557-559. (https://doi.org/10.1200/go.20.00097)

Fan C, Li K, Ding Y, Lu Lu W \& Wang J 2020 ACE2 expression in kidney and testis may cause kidney and testis damage after 2019nCoV infection. medRxiv [epub]. (https://doi.org/10.1101/2020.02.12. 20022418)
Han C, Duan C, Zhang S, Spiegel B, Shi H, Wang W, Zhang L, Lin R, Liu J, Ding Z, et al. 2020 Digestive Symptoms in COVID-19 patients with mild disease severity: clinical presentation, stool viral RNA testing, and outcomes. American Journal of Gastroenterology 115 916-923. (https://doi.org/10.14309/ajg.0000000000000664)

Hanna TP, Evans GA \& Booth CM 2020 Cancer, COVID-19 and the precautionary principle: prioritizing treatment during a global pandemic. Nature Reviews Clinical Oncology 17 268-270. (https://doi. org/10.1038/s41571-020-0362-6)

Hoffmann M, Kleine-Weber H, Schroeder S, Kruger N, Herrler T, Erichsen S, Schiergens TS, Herrler G, Wu NH, Nitsche A, et al. 2020 SARS-CoV-2 cell entry depends on ACE2 and TMPRSS2 and is blocked by a clinically proven protease inhibitor. Cell 181 271-280. (https://doi.org/10.1016/j.cell.2020.02.052)

Huang C, Wang Y, Li X, Ren L, Zhao J, Hu Y, Zhang L, Fan G, Xu J, Gu X, et al. 2020 Clinical features of patients infected with 2019 novel coronavirus in Wuhan, China. Lancet 395 497-506. (https:// doi.org/10.1016/s0140-6736(20)30183-5)

Huggins C 1942 Effect of orchiectomy and irradiation on cancer of the prostate. Annals of Surgery 115 1192-1200.

Imai Y, Kuba K, Rao S, Huan Y, Guo F, Guan B, Yang P, Sarao R, Wada T, Leong-Poi $\mathrm{H}$, et al. 2005 Angiotensin-converting enzyme 2 protects from severe acute lung failure. Nature 436 112-116. (https://doi. org/10.1038/nature03712)

Imamoto T, Suzuki $\mathrm{H}$, Utsumi T, Takano $\mathrm{M}$, Suyama T, Kawamura $\mathrm{K}$, Kamiya N, Naya Y, Ueda T \& Ichikawa T 2010 External validation of a nomogram predicting the probability of prostate cancer Gleason sum upgrading between biopsy and radical prostatectomy pathology among Japanese patients. Urology 76 404-410. (https://doi. org/10.1016/j.urology.2009.05.084)

Imamoto T, Suzuki H, Yano M, Kawamura K, Kamiya N, Araki K, Komiya A, Nihei N, Naya Y \& Ichikawa T 2008 The role of testosterone in the pathogenesis of prostate cancer. International Journal of Urology 15 472-480. (https://doi. org/10.1111/j.1442-2042.2008.02074.x)

Jia HP, Look DC, Shi L, Hickey M, Pewe L, Netland J, Farzan M, Wohlford-Lenane C, Perlman S \& McCray PB Jr 2005 ACE2 receptor expression and severe acute respiratory syndrome coronavirus infection depend on differentiation of human airway epithelia. Journal of Virology 79 14614-14621. (https://doi.org/10.1128/ jvi.79.23.14614-14621.2005)

Jin J, Bai P, He W, Wu F, Liu X, Han D, Liu S \& Yang J 2020a Gender differences in patients with COVID-19: focus on severity and mortality. Frontiers in Public Health 8 152. (https://doi.org/10.3389/ fpubh.2020.00152)

Jin Y, Yang H, Ji W, Wu W, Chen S, Zhang W \& Duan G $2020 b$ Virology, epidemiology, pathogenesis, and control of COVID-19. Viruses 12 372. (https://doi.org/10.3390/v12040372)

Klein SL 2012 Sex influences immune responses to viruses, and efficacy of prophylaxis and treatments for viral diseases. Bioessays $\mathbf{3 4}$ 1050-1059. (https://doi.org/10.1002/bies.201200099)

Klotz L, Boccon-Gibod L, Shore ND, Andreou C, Persson BE, Cantor P, Jensen JK, Olesen TK \& Schroder FH 2008 The efficacy and safety of degarelix: a 12-month, comparative, randomized, open-label, parallel-group phase III study in patients with prostate cancer. BJU International 102 1531-1538. (https://doi. org/10.1111/j.1464-410x.2008.08183.x)

Kluth LA, Shariat SF, Kratzik C, Tagawa S, Sonpavde G, Rieken M, Scherr DS \& Pummer K 2014 The hypothalamic-pituitary-gonadal axis and prostate cancer: implications for androgen deprivation therapy. World Journal of Urology 32 669-676. (https://doi. org/10.1007/s00345-013-1157-5)

Kutikov A, Weinberg DS, Edelman MJ, Horwitz EM, Uzzo RG \& Fisher RI 2020 A war on two fronts: cancer care in the time of COVID-19. Annals of Internal Medicine 172 756-758. (https://doi.org/10.7326/ $\mathrm{m} 20-1133)$ 
Li D, Jin M, Bao P, Zhao W \& Zhang S 2020a Clinical characteristics and results of semen tests among men with coronavirus disease 2019 . JAMA Network Open 3 e208292. (https://doi.org/10.1001/ jamanetworkopen.2020.8292)

Li Q, Guan X, Wu P, Wang X, Zhou L, Tong Y, Ren R, Leung KSM, Lau EHY, Wong JY, et al. 2020b Early transmission dynamics in Wuhan, China, of novel coronavirus-infected pneumonia. New England Journal of Medicine 382 1199-1207. (https://doi.org/10.1056/ nejmoa2001316)

Liang W, Guan W, Chen R, Wang W, Li J, Xu K, Li C, Ai Q, Lu W, Liang H, et al. 2020 Cancer patients in SARS-CoV-2 infection: a nationwide analysis in China. Lancet Oncology 21 335-337. (https://doi.org/10.1016/s1470-2045(20)30096-6)

Lukassen S, Chua RL, Trefzer T, Kahn NC, Schneider MA, Muley T, Winter H, Meister M, Veith C, Boots AW, et al. 2020 SARS-CoV-2 receptor ACE2 and TMPRSS2 are primarily expressed in bronchial transient secretory cells. EMBO Journal 39 e105114. (https://doi. org/10.15252/embj.20105114)

Ma L, Xie W, Li D, Shi L, Mao Y, Xiong Y, Zhang Y \& Zhang M 2020 Effect of SARS-CoV-2 infection upon male gonadal function: a single center-based study. medRxiv [epub]. (https://doi.org/10.1101/2020.03. 21.20037267)

Mikkonen L, Pihlajamaa P, Sahu B, Zhang FP \& Janne OA 2010 Androgen receptor and androgen-dependent gene expression in lung. Molecular and Cellular Endocrinology 317 14-24. (https://doi. org/10.1016/j.mce.2009.12.022)

Mishra JS, Hankins GD \& Kumar S 2016 Testosterone downregulates angiotensin II type-2 receptor via androgen receptor-mediated ERK1/2 MAP kinase pathway in rat aorta. Journal of the ReninAngiotensin-Aldosterone System 171470320316674875 . (https://doi. org/10.1177/1470320316674875)

Moilanen AM, Riikonen R, Oksala R, Ravanti L, Aho E, Wohlfahrt G, Nykanen PS, Tormakangas OP, Palvimo JJ \& Kallio PJ 2015 Discovery of ODM-201, a new-generation androgen receptor inhibitor targeting resistance mechanisms to androgen signaling-directed prostate cancer therapies. Scientific Reports 5 12007. (https://doi.org/10.1038/ srep12007)

Monteil V, Kwon H, Prado P, Hagelkrüys A, Wimmer RA, Stahl M, Leopoldi A, Garreta E, Hurtado del Pozo C, Prosper F, et al. 2020 Inhibition of SARS-CoV-2 infections in engineered human tissues using clinical-grade soluble human ACE2. Cell 181 905-913.e7. (https://doi.org/10.1016/j.cell.2020.04.004)

Montopoli M, Zumerle S, Vettor R, Rugge M, Zorzi M, Catapano CV, Carbone GM, Cavalli A, Pagano F, Ragazzi E, et al. 2020 Androgendeprivation therapies for prostate cancer and risk of infection by SARS-CoV-2: a population-based study $(\mathrm{n}=4532)$. Annals of Oncology [epub]. (https://doi.org/10.1016/j.annonc.2020.04.479)

National Comprehensive Cancer Network 2020 Management of prostate cancer during the COVID-19 pandemic. Plymouth Meeting, PA, USA: NCCN. (available at: https://www.nccn.org/covid-19/pdf/NCCN PCa_COVID_guidelines.pdf)

O'Donnell A, Judson I, Dowsett M, Raynaud F, Dearnaley D, Mason M, Harland S, Robbins A, Halbert G, Nutley B, et al. 2004 Hormonal impact of the 17alpha-hydroxylase/C $(17,20)$-lyase inhibitor abiraterone acetate (CB7630) in patients with prostate cancer. British Journal of Cancer 90 2317-2325. (https://doi.org/10.1038/sj.bjc.6601879)

Onder G, Rezza G \& Brusaferro S 2020 Case-fatality rate and characteristics of patients dying in relation to COVID-19 in Italy. JAMA [epub]. (https://doi.org/10.1001/jama.2020.4683)

Park SE 2020 Epidemiology, virology, and clinical features of severe acute respiratory syndrome -coronavirus-2 (SARS-CoV-2; coronavirus disease-19). Clinical and Experimental Pediatrics 63 119-124. (https:// doi.org/10.3345/cep.2020.00493)

Riviere G, Michaud A, Breton C, VanCamp G, Laborie C, Enache M, Lesage J, Deloof S, Corvol P \& Vieau D 2005 Angiotensin-converting enzyme 2 (ACE2) and ACE activities display tissue-specific sensitivity to undernutrition-programmed hypertension in the adult rat. Hypertension 46 1169-1174. (https://doi.org/10.1161/01. hyp.0000185148.27901.fe)

Stopsack KH, Mucci LA, Antonarakis ES, Nelson PS \& Kantoff PW 2020 TMPRSS2 and COVID-19: serendipity or opportunity for intervention? Cancer Discovery 10 779-782. (https://doi. org/10.1158/2159-8290.cd-20-0451)

Tang N, Bai H, Chen X, Gong J, Li D \& Sun Z 2020 Anticoagulant treatment is associated with decreased mortality in severe coronavirus disease 2019 patients with coagulopathy. Journal of Thrombosis and Haemostasis 18 1094-1099. (https://doi.org/10.1111/ jth.14817)

Taplin ME, Montgomery B, Logothetis CJ, Bubley GJ, Richie JP, Dalkin BL, Sanda MG, Davis JW, Loda M, True LD, et al. 2014 Intense androgen-deprivation therapy with abiraterone acetate plus leuprolide acetate in patients with localized high-risk prostate cancer: results of a randomized phase II neoadjuvant study. Journal of Clinical Oncology 32 3705-3715. (https://doi.org/10.1200/ jco.2013.53.4578)

Tombal B, Borre M, Rathenborg P, Werbrouck P, Van Poppel H, Heidenreich A, Iversen P, Braeckman J, Heracek J, Baskin-Bey E, et al. 2015 Long-term efficacy and safety of enzalutamide monotherapy in hormone-naive prostate cancer: 1- and 2-year open-label follow-up results. European Urology 68 787-794. (https://doi.org/10.1016/j. eururo.2015.01.027)

Tomlins SA, Laxman B, Varambally S, Cao X, Yu J, Helgeson BE, Cao Q, Prensner JR, Rubin MA, Shah RB, et al. 2008 Role of the TMPRSS2ERG gene fusion in prostate cancer. Neoplasia 10 177-188. (https:// doi.org/10.1593/neo.07822)

Walls AC, Park YJ, Tortorici MA, Wall A, McGuire AT \& Veesler D 2020 Structure, function, and antigenicity of the SARS-CoV-2 spike glycoprotein. Cell 181 281-292.e6. (https://doi.org/10.1016/j. cell.2020.02.058)

Wang X, Dhindsa R, Povysil G, Zoghbi A, Motelow J, Hostyk J \& Goldstein D 2020 Transcriptional inhibition of host viral entry proteins as a therapeutic strategy for SARS-CoV-2. Preprints 2020 [epub]. (https://doi.org/10.20944/preprints202003.0360.v1)

Wang Z \& Xu X 2020 scRNA-seq profiling of human testes reveals the presence of the ACE2 receptor, a target for SARS-CoV-2 infection in Spermatogonia, Leydig and Sertoli cells. Cells 9 920. (https://doi. org/10.3390/cells9040920)

Wukich C 2015 Social media use in emergency management. Journal of Emergency Management 13 281-294. (https://doi.org/10.5055/ jem.2015.0242)

Xydakis MS, Dehgani-Mobaraki P, Holbrook EH, Geisthoff UW, Bauer C, Hautefort C, Herman P, Manley GT, Lyon DM \& Hopkins C 2020 Smell and taste dysfunction in patients with COVID-19. Lancet Infectious Diseases [epub]. (https://doi.org/10.1016/s14733099(20)30293-0)

Yu J, Ouyang W, Chua MLK \& Xie C 2020 SARS-CoV-2 transmission in patients with cancer at a tertiary care hospital in Wuhan, China. JAMA Oncology [epub]. (https://doi.org/10.1001/ jamaoncol.2020.0980)

Yu J, Yu J, Mani RS, Cao Q, Brenner CJ, Cao X, Wang X, Wu L, Li J, $\mathrm{Hu}$ M, et al. 2010 An integrated network of androgen receptor, polycomb, and TMPRSS2-ERG gene fusions in prostate cancer progression. Cancer Cell 17 443-454. (https://doi.org/10.1016/j. ccr.2010.03.018)

Yuan M, Wu NC, Zhu X, Lee CD, So RTY, Lv H, Mok CKP \& Wilson IA 2020 A highly conserved cryptic epitope in the receptor binding domains of SARS-CoV-2 and SARS-CoV. Science 368 630-633. (https://doi.org/10.1126/science.abb7269)

Zhou F, Yu T, Du R, Fan G, Liu Y, Liu Z, Xiang J, Wang Y, Song B, Gu X, et al. 2020 Clinical course and risk factors for mortality of adult
(C) 2020 Society for Endocrinology Published by Bioscientifica Ltd. Printed in Great Britain 
inpatients with COVID-19 in Wuhan, China: a retrospective cohort study. Lancet 395 1054-1062. (https://doi.org/10.1016/s01406736(20)30566-3)

Ziegler CGK, Allon SJ, Nyquist SK, Mbano IM, Miao VN, Tzouanas CN, Cao Y, Yousif AS, Bals J, Hauser BM, et al. 2020 SARS-CoV-2 receptor ACE2 is an interferon-stimulated gene in human airway epithelial cells and is detected in specific cell subsets across tissues. Cell 181 1016-1035.e19. (https://doi. org/10.1016/j.cell.2020.04.035)

Zou X, Chen K, Zou J, Han P, Hao J \& Han Z 2020 Single-cell RNA-seq data analysis on the receptor ACE2 expression reveals the potential risk of different human organs vulnerable to $2019-\mathrm{nCoV}$ infection. Frontiers of Medicine 14 185-192. (https://doi.org/10.1007/s11684020-0754-0)

Received in final form 1 June 2020

Accepted 4 June 2020

Accepted Manuscript published online 5 June 2020
C) 2020 Society for Endocrinology Published by Bioscientifica Ltd. Printed in Great Britain 